\title{
Atrial Fibrillation Induction in a Pediatric Patient during Adenosine Administration
}

\author{
Jeffrey A. Robinson, Christopher S. Snyder* \\ The Congenital Heart Collaborative, Rainbow Babies and Children's Hospital, Case Western Reserve University School \\ of Medicine, Cleveland, OH, USA \\ Email: *Christopher.Snyder@UHhospitals.org
}

How to cite this paper: Robinson, J.A. and Snyder, C.S. (2017) Atrial Fibrillation Induction in a Pediatric Patient during Adenosine Administration. World Journal of Cardiovascular Diseases, 7, 57-63.

https://doi.org/10.4236/wjcd.2017.73006

Received: December 20, 2016

Accepted: March 5, 2017

Published: March 8, 2017

Copyright $(9) 2017$ by authors and Scientific Research Publishing Inc. This work is licensed under the Creative Commons Attribution International License (CC BY 4.0).

http://creativecommons.org/licenses/by/4.0/

\begin{abstract}
Adenosine by rapid intravenous bolus is frequently utilized in clinical practice as both a pharmacologic treatment for supraventricular (reentrant) tachycardia and in provocative testing for the diagnosis of Wolff-Parkinson-White (WPW) syndrome. This is a case report of an otherwise healthy adolescent female who received adenosine during a provocative test for WPW syndrome. Immediately after receiving adenosine, the patient had a self-limited episode of atrial fibrillation. When administering adenosine, teams should be aware of the potential adverse effects and be prepared to treat appropriately.
\end{abstract}

\section{Keywords}

Pediatric, Adolescent, Electrophysiology, Atrial Fibrillation, Adenosine

\section{Introduction}

Palpitations are a common occurrence in pediatric and adolescent patients. Their evaluation includes history, physical exam, and electrocardiogram (ECG) to assist the physician in reaching the appropriate diagnosis. This is a case report of an adolescent female presenting with ongoing palpitations, which had an ECG with a short PR interval and a potential delta wave, raising suspicion for WolffParkinson-White (WPW) syndrome. Due to her ECG abnormalities and history of palpitations, she was referred for adenosine challenge. Immediately after the adenosine bolus was administered, the patient experienced a self-limited episode of atrial fibrillation.

\section{Case Report}

A 17-year-old, Caucasian female, with history of depression and anxiety, was referred to pediatric cardiology with a 1.5 -year history of episodic palpitations 
(Table 1). Her past medical/surgical history and review of systems were negative. She denied alcohol and illicit drug use and had no family history of arrhythmia, congenital heart disease, cardiomyopathy, or sudden cardiac death.

The patient had normal vital signs, including heart rate of 79 beats per minute (bpm) and blood pressure of $103 / 67 \mathrm{mmHg}$. She was noted to have a regular rhythm with an otherwise normal physical exam. A 15-lead ECG revealed normal sinus rhythm, PR interval of 122 milliseconds (ms), and corrected QT interval (QTc) of $413 \mathrm{~ms}$. Laboratory testing demonstrated normal electrolytes and negative urine drug screen.

To complete her evaluation, the patient wore a 48-hour ambulatory heart rate monitor (ZIO ${ }^{\circ}$ XT Patch, iRhythm Technologies, Inc., San Francisco, CA, USA), which recorded a regular rhythm with rare $(<1 /$ day $)$ premature atrial contractions (PACs) and premature ventricular contractions (PVCs). All patient event markers, including a symptom diary entry of heart "pounding", correlated with normal sinus rhythm at a rate of $<100 \mathrm{bpm}$; however, her tracings also demonstrated an intermittent short PR interval and questionable delta wave.

Due to her ECG, coupled with the chief complaint ofpalpitations, there was a concern for WPW syndrome. The patient was referred to the Pediatric Electrophysiology Lab for an adenosine challenge. Consent was obtained from the patient and her mother. A peripheral IV was started in the right antecubital fossa and she was placed on a continuous ECG monitor. Her baseline heart rhythm was normal sinus rhythm at a rate of $90 \mathrm{bpm}$. Adenosine $12 \mathrm{mg}$ was administered by rapid IV push followed by a 10-milliliter saline flush. After a short delay, A-V node block was noted, with multiple non-conducted P-waves (Figure $1)$.

After 6.5 seconds, the patient went into atrial fibrillation, which persisted for 45 seconds, then self-terminated. The patient remained stable during this period with normal blood pressure and verbal response. Of note, the patient described her episode of atrial fibrillation as qualitatively different from her palpitations. In spite of inducing atrial fibrillation, the adenosine challenge was effective in ruling out accessory pathway atrioventricular conduction and WPW syndrome in this patient due to atrioventricular block.

Table 1. Sociodemographic and baseline clinical characteristics of the patient. bpm = beats per minute.

\begin{tabular}{cc}
\hline Age (years) & 17 \\
\hline Ethnicity and gender & Caucasian female \\
Weight $(\mathrm{kg})$ & 61.7 \\
Height $(\mathrm{cm})$ & 154 \\
Body mass index $\left(\mathrm{kg} / \mathrm{m}^{2}\right)$ & 25.7 \\
Resting heart rate $(\mathrm{bpm})$ & 79 \\
Resting blood pressure $(\mathrm{mmHg})$ & $103 / 67$ \\
\hline
\end{tabular}



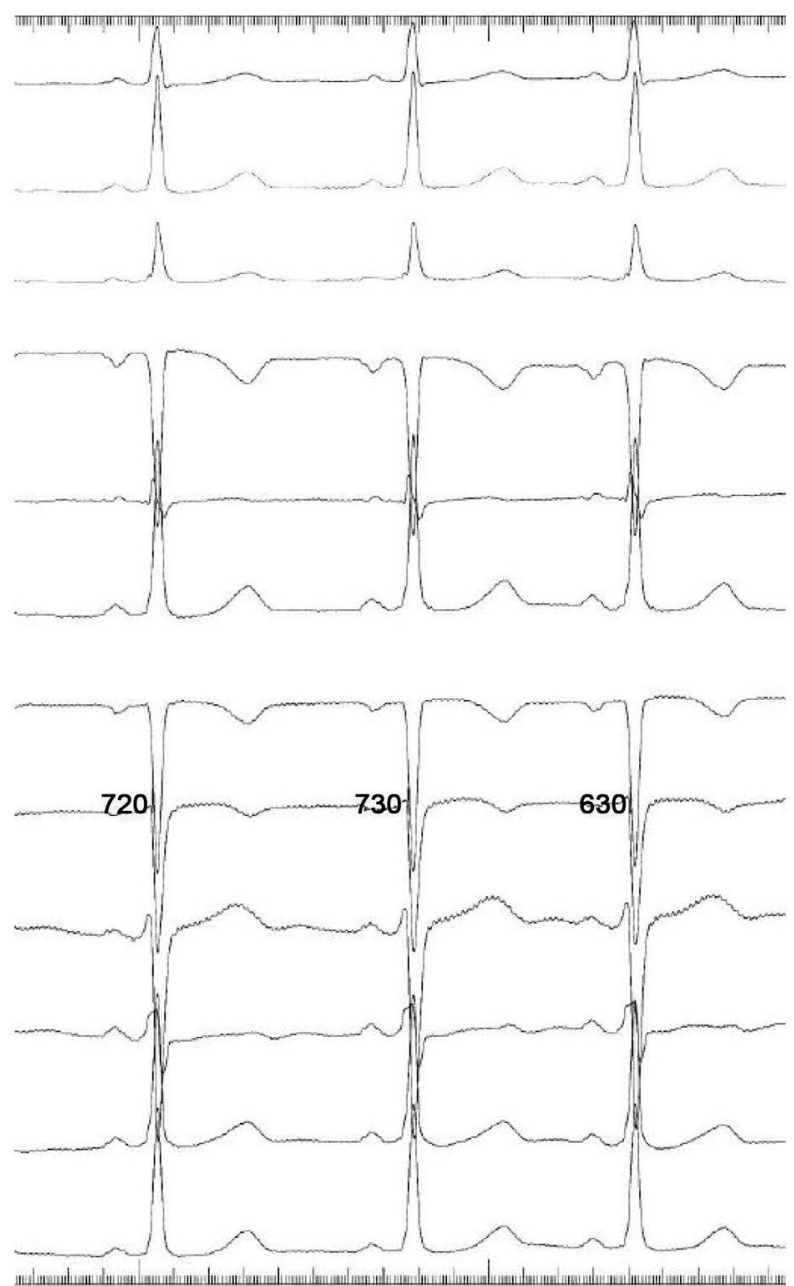

(a)

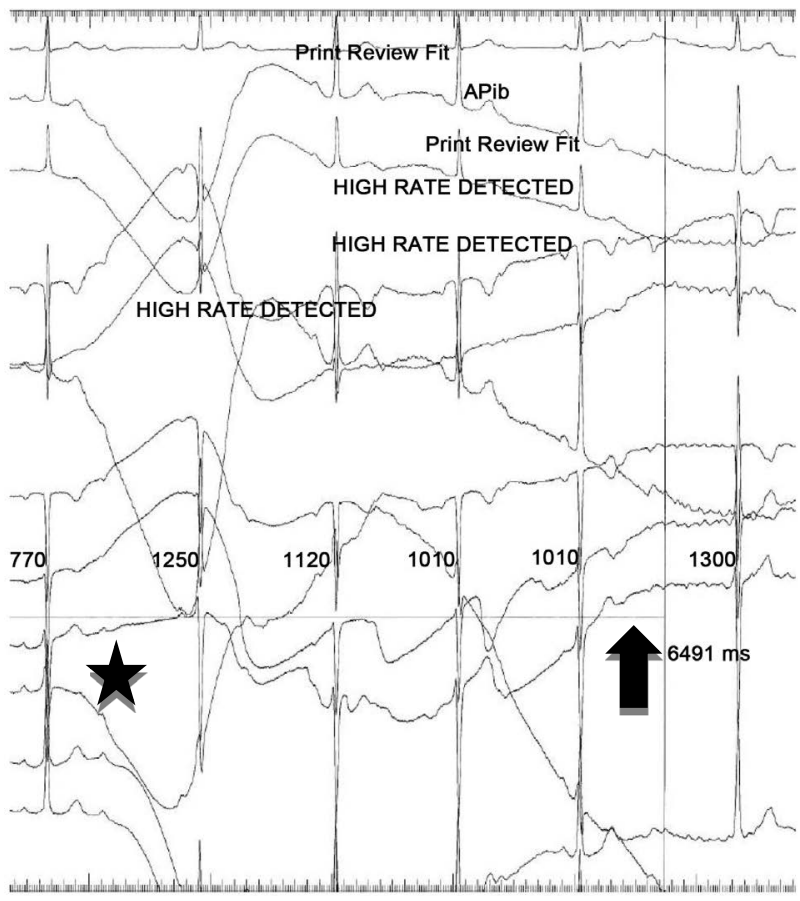

(b) 


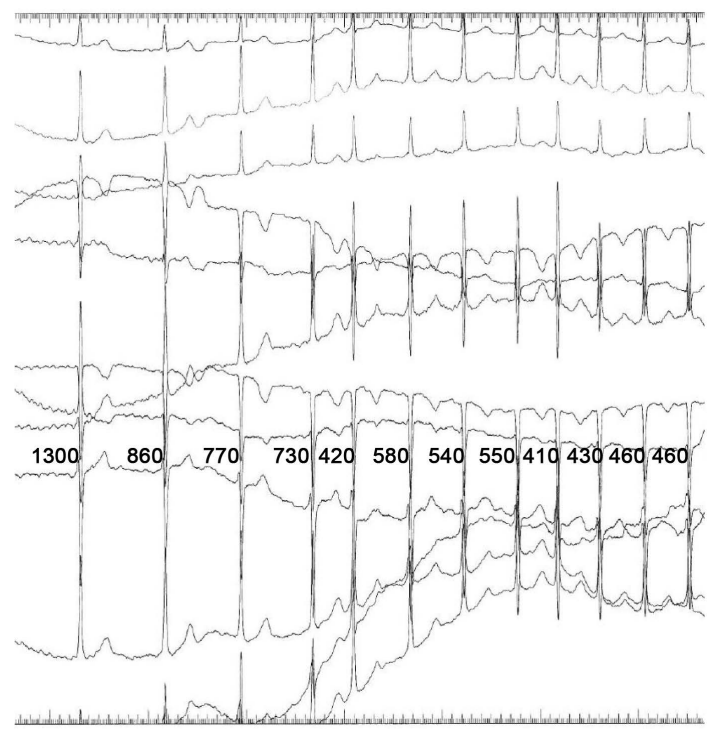

(c)
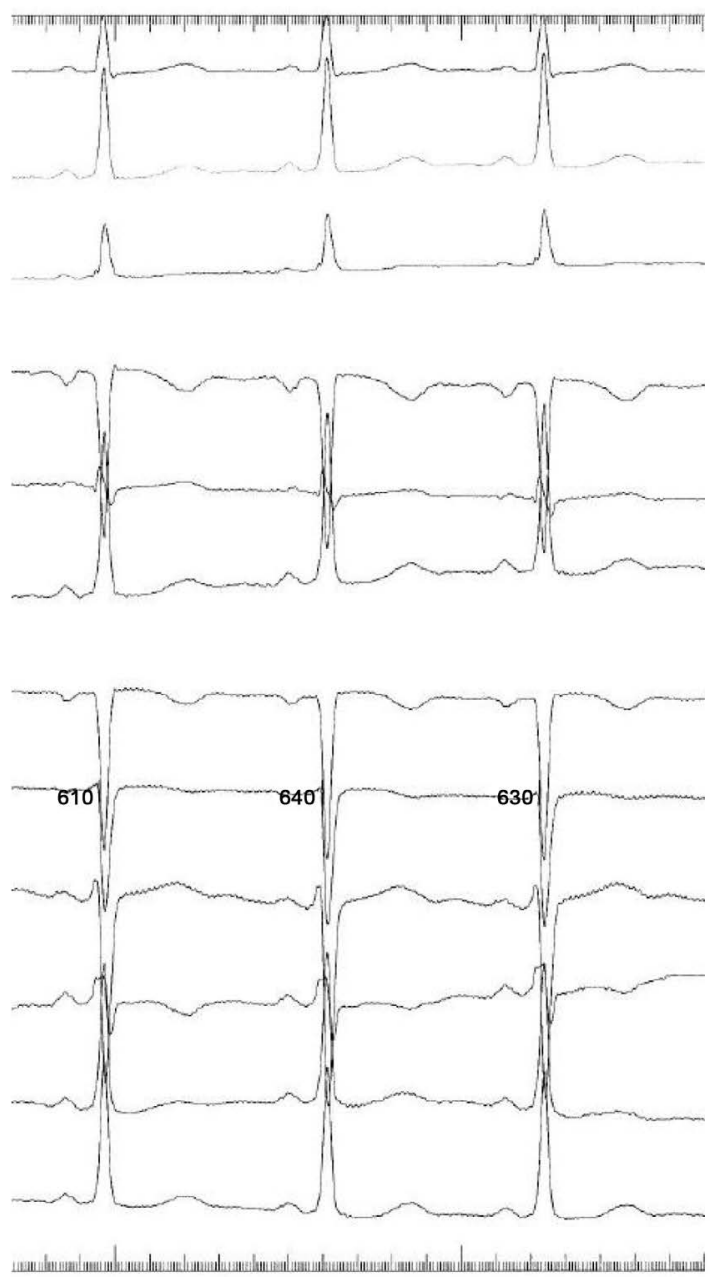

(d)

Figure 1. (a) Normal sinus rhythm is demonstrated at baseline; (b) After adenosine is administered, there is atrioventricular block (star), followed by spontaneous onset of atrial fibrillation (arrow); (c) Atrial fibrillation; (d) Return to normal sinus rhythm is demonstrated following spontaneous cardioversion from atrial fibrillation. 
The patient was observed for one hour prior to discharge to home, without further concerns or complications. At outpatient follow-up one month later, the frequency of palpitations had decreased after the patient had eliminated caffeinated beverages from her diet. The patient was discharged and has not required further outpatient visits with cardiology.

\section{Discussion}

History, physical exam, and ECG are the hallmarks of the clinical evaluation for underlying arrhythmia in adolescents presenting with palpitations. In cases of patients with palpitations such as this, where a short PR interval and delta wave on 48-hour monitorraised the suspicion for a WPW conduction pathway, further investigation should be considered. Here, adenosine was used to observe any potential antegrade conduction by an accessory pathway while the AV node is temporarily blocked. This diagnostic use of adenosine has been well-described [1] [2] [3].

While the therapeutic utility of adenosine is documented for patients in a narrow complex tachycardia, potential acute adverse effects of the medication have been described in pediatric patients, including induction of atrial fibrillation, accelerated ventricular tachycardia, apnea, and asystole lasting up to one minute [3]. Atrial fibrillation in this setting is usually transient and not sustained [1]. An acute shortening of the atrial refractory period has been proposed as the mechanism by which adenosine can precipitate atrial fibrillation [4]. A second mechanism may exist, consequent to an adenosine-induced catecholamine burst resulting in increased PACs [5]. Whereas most instances of atrial fibrillation occurring after adenosine administration have been reported in patients with known tachycardia or accessory pathways, the mechanism of acute shortening of the atrial refractory period may explain how atrial fibrillation could develop in a patient with otherwise normal conduction, as in the case report described herein [6].

The overall incidence of atrial fibrillation after adenosine administration is unknown. In a prospective series of 200 adult patients with known paroxysmal supraventricular tachycardia (SVT) referred for EP study, $12 \%$ of patients developed atrial fibrillation with or without atrial flutter following administration of adenosine $12 \mathrm{mg}$ IV [7] [8]. Regardless, the frequency of atrial fibrillation after adenosine in the general population cannot be extrapolated. Cautious use of adenosine in patients with a preexisting diagnosis of atrial fibrillation has been empirically advised [6]. Regardless, it has been observed that in the series of patients with atrial fibrillation after adenosine administration, none had a prior diagnosis of atrial fibrillation [5].

When administering adenosine, physicians must be able to recognize and respond to the potential acute adverse effects of the medication, including resultant arrhythmias. As such, team members should have assigned roles prior to the start of a case in order to efficiently perform defibrillation, if necessary. Defibrillation equipment should be immediately available and ready. Patients and fami- 
lies should be aware of the small risk for arrhythmia associated with adenosine. Although the episode of atrial fibrillation described herein was brief and resolved spontaneously, adenosine should only be administered in settings where appropriate monitoring is available and healthcare staff are able to recognize and treat complications.

\section{Conclusion}

This is a case report of acute, self-resolving atrial fibrillation as a consequence to adenosine administration in an adolescent patient presenting with concern for a short PR interval and delta wave on ambulatory ECG monitoring. Due to the AV conduction block noted immediately following adenosine, the presence of an accessory pathway was virtually excluded. Atrial fibrillation may be an adverse effect of adenosine administration and physicians that administer it should be prepared to respond appropriately.

\section{Disclosures}

This article is original, with no portion under simultaneous consideration for publication elsewhere or previously published. All authors have read and approve this submission.

\section{References}

[1] Malcolm, A.D., Garratt, C.J. and Camm, A.J. (1993) The Therapeutic and Diagnostic Cardiac Electrophysiological Uses of Adenosine. Cardiovascular Drugs and Therapy, 7, 139-147. https://doi.org/10.1007/BF00878323

[2] Hoyt, W.J.J., Thomas, P.E. and Snyder, C.S. (2012) Induction of Atrial Fibrillation with Adenosine during a Transesophageal Electrophysiology Study to Risk Stratify a Patient with Asymptomatic Ventricular Preexcitation. Congenital Heart Disease, 8, E99-E101. https://doi.org/10.1111/j.1747-0803.2012.00682.x

[3] Crosson, J.E., Etheridge, S.P., Milstein, S., et al. (1994) Therapeutic and Diagnostic Utility of Adenosine during Tachycardia Evaluation in Children. American Journal of Cardiology, 74, 155-160. https://doi.org/10.1016/0002-9149(94)90089-2

[4] Wilbur, S.L. and Marchlinski, F.E. (1997) Adenosine as an Antiarrhythmic Agent. American Journal of Cardiology, 79, 30-37. https://doi.org/10.1016/S0002-9149(97)00261-0

[5] Szentmiklosi, A.J., Galajda, Z., Cseppento, Á., et al. (2015) The Janus Face of Adenosine: Antiarrhythmic and Proarrhythmic Actions. Current Pharmaceutical Design, 21, 965-976. https://doi.org/10.2174/1381612820666141029100346

[6] Zehender, M., Jeron, A., Faber, T., et al. (1996) Adenosine in Treating Cardiac Arrhythmias. Journal of Autonomic Pharmacology, 16, 329-331. https://doi.org/10.1111/j.1474-8673.1996.tb00046.x

[7] Strickberger, S.A., Man, K.C., Daoud, E.G., et al. (1997) Adenosine-Induced Atrial Arrhythmia: A Prospective Analysis. Annals of Internal Medicine, 127, 417-422. https://doi.org/10.7326/0003-4819-127-6-199709150-00001

[8] Glatter, K.A., Cheng, J., Dorostkar, P., et al. (1999) Electrophysiologic Effects of Adenosine in Patients with Supraventricular Tachycardia. Circulation, 99, 10341040. https://doi.org/10.1161/01.CIR.99.8.1034 


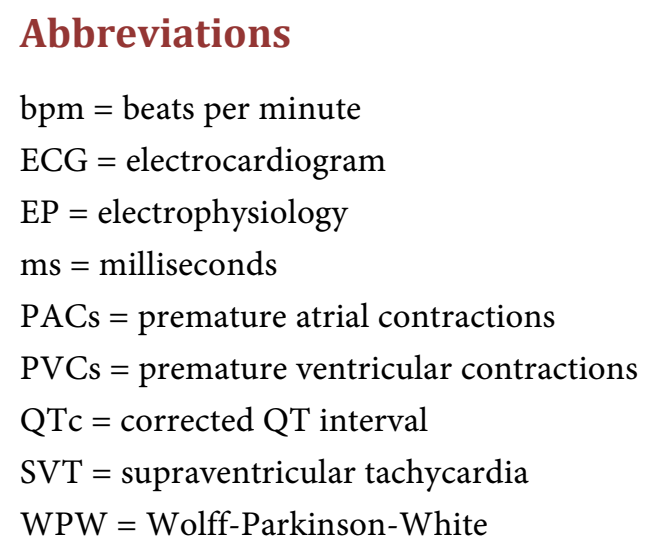

Submit or recommend next manuscript to SCIRP and we will provide best service for you:

Accepting pre-submission inquiries through Email, Facebook, LinkedIn, Twitter, etc. A wide selection of journals (inclusive of 9 subjects, more than 200 journals)

Providing 24-hour high-quality service

User-friendly online submission system

Fair and swift peer-review system

Efficient typesetting and proofreading procedure

Display of the result of downloads and visits, as well as the number of cited articles Maximum dissemination of your research work

Submit your manuscript at: http://papersubmission.scirp.org/

Or contact wjcd@scirp.org 